\title{
Author Correction: Air pollution reduction and climate co-benefits in China's industries
}

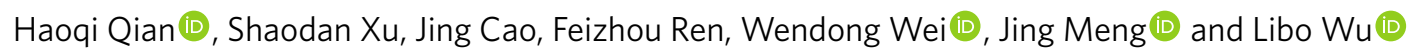

Correction to: Nature Sustainability https://doi.org/10.1038/s41893-020-00669-0, published online 4 January 2021.

In the version of this Article originally published, in the third sentence of the abstract, the value ' 80 ' should have been ' 80,000 '.

The sentence 'We construct and analyse a firm-level database covering nearly 80 observations and use scenario simulations to estimate the co-benefits.' was corrected to 'We construct and analyse a firm-level database covering nearly 80,000 observations and use scenario simulations to estimate the co-benefits.'

Published online: 15 January 2021

https://doi.org/10.1038/s41893-021-00683-w

() The Author(s), under exclusive licence to Springer Nature Limited 2021 